\title{
Implementation of Automatic Identification Technology in a Process of Fixture Assembly/Disassembly
}

\author{
Gordana Ostojic ${ }^{1}{ }^{*}$ - Stevan Stankovski ${ }^{1}$ - Djordje Vukelic ${ }^{1}$ - Milovan Lazarevic ${ }^{1}$ - Janko Hodolic ${ }^{1}-$ \\ Branko Tadic ${ }^{2}$ - Stevan Odri ${ }^{1}$ \\ 1 University of Novi Sad, Faculty of Technical Science, Serbia \\ 2 University of Kragujevac, Faculty of Mechanical Engineering, Serbia
}

\begin{abstract}
Radio Frequency Identification (RFID) technology presents automatic identification technology that can be used in product life cycle various phases, especially in the manufacturing phase. The analysis of possible application of RFID technology in machining and inspection operations for fixture manufacturing assembly/disassembly process is presented in this paper. Furthermore, assemble/disassemble fixture manufacturing system structure and conception is presented. An analysis involves hardware and software components that the designed system for assembly/disassembly needs to have. Suggested system verification was done in laboratory conditions. Verification uses ninety-six parts and adequate fixtures. The paper concludes with final remarks, discussing advantages and disadvantages of the developed system.

(C)2011 Journal of Mechanical Engineering. All rights reserved.
\end{abstract}

Keywords: fixture, automatic identification, RFID technology

\section{INTRODUCTION}

Modern manufacturing is characterized by large product ranges, frequent changes of production programmes, constant demands for higher product quality, etc. Two important factors which allow the integration of the mentioned characteristics are scheduling and organisation. Scheduling represents the allocation of scarce sources to tasks in a definite period of time [1]. One of the basic requirements of every production system is production optimization, which is the minimization of production time and costs, on the one hand, and maximization of profit, on the other [2]. The efficiency of the machining process is influenced by numerous parameters, one of which is fixtures. Fixtures are used to reliably locate and clamp the workpiece during a number of operations (machining, welding, inspection, etc.), which are all part of manufacturing. Fixtures significantly influence the output effects of the production process, bearing in mind that costs of fixture manufacture can contribute to the total manufacturing costs [3] by more than $20 \%$. Such percentage ratio confirms the fact that those are expensive and high-quality devices, while their design and manufacture deserve special attention.
Considering the costs and time consumption, the manufacture of novel fixture design solutions can be broken down into two key processes:

- fixture design process,

- fixture assembly/disassembly process.

All other processes needed to manufacture a fixture (e.g. inspection of assembly precision) require less time while incurring lower costs.

The majority of investigations have so far focused on the specific area of development of methodologies for fixture design. So far, many different approaches have been attempted in the research of fixture design. Specifically, it can be discerned between several fields of research in this area. Most of them refer to the development of fixture design systems and the development of methodologies for fixture design optimization. Numerous techniques have been employed to optimize fixture design including artificial neural networks (ANN) [4], finite element analysis (FEA) [5], genetic algorithms (GA) [6], as well as combinations of some methods such as FEA and GA [7], ACA and FEA [8], and GA and ant colony algorithm (ACA) [9]. Those techniques of optimization were generally focused on defining optimal location for certain fixture elements, predominantly the locating and/or clamping 
elements. Minimization of workpiece deformation under the influence of forces was the most often used goal function. This allowed a definition of all the suitable locations for particular fixture elements. Nevertheless, the main drawback of this approach stems from the fact that it fails to provide a selection of specific fixture elements as well as the final fixture solution. These questions were addressed by the research focused on the development of fixture design systems. With respect to the development of fixture design systems, there exist a number of viable approaches: expert systems [10] and [11], systems based on ANN [12], systems based on case-based reasoning (CBR) methodology [13] and [14], and other knowledge-based systems [15] and [16]. Each of them can be attributed particular advantages and disadvantages.

Much less attention has been paid to the problem of fixture assembly/disassembly. The most frequently applied methodologies have been: feature-based methodology [17] and [18], knowledge-based methodology [19], geometrybased methodology [20] and [21], and virtual reality-based methodology [22]. To verify their methodologies, researchers have used various CAD systems. However, the main issue with these research works is that they pertain to fixture assembly planning while disregarding the process of physical fixture assembly/disassembly. These methodologies are based on theoretical knowledge and software simulations of fixture assembly which have not been tested in practice, either in laboratory or in industrial environment.

Assembly and disassembly are parts of the production process and are crucial factors in the competitiveness of the industry in general [23]. These processes have a growing impact on fixture manufacture considering that complex workpieces require complex fixtures. Some fixture designs contain more than 150 elements. A large number of fixture elements also prolongs the time required for fixture assembly/disassembly. According to the published research, the time and cost share of the assembly and disassembly ranges from 15 to $25 \%$, depending on the number of fixture elements and its complexity. This percentage indicates that special attention must be paid to the very process of efficient assembly/disassembly of fixtures in order to increase productivity and lower the total costs of manufacture.

Bearing in mind their importance for the production process, the automation of fixture design, assembly/disassembly and identification should be realized to advance the complete process. The automation should primarily involve automatic identification of fixtures during the assembly/disassembly. In this paper, the emphasis is placed on the improvement of the process through shortening of their duration, through automated identification of fixture elements and fixture assemblies.

\section{RFID TECHNOLOGY}

Radio Frequency Identification (RFID) is a system for automated data identification and acquisition [24], which allows collection and wireless (radio wave) transfer of productionand business-related data. Since the moment, a product/fixture is manufactured, to the beginning of its exploitation or disassembly, RFID technology allows real-time identification, during delivery, storage, or any other process taking place within an enterprise. By means of radio waves, the data are acquisitioned and transferred in a wireless mode between production and business processes in real time. This unique way of identification is adjusted in such a way that it allows the information on product/fixture to correspond to the information on the side of the company or the host system. Using RFID technology, it is possible to track products and equipment, including fixtures, with minimum human intervention. This can potentially cut back operating costs and increase real-time visibility during the complete product/fixture life cycle.

The RFID system consists of: a computer (or PLC), RFID reader, antenna (which can be integrated in a RFID reader) and transponder tag. The antenna is used to amplify the signal, which is emitted by the reader to the tag, as well as the signal, which is returned to the reader by the tag, which increases the tag-reading range. The RFID reader can be a stationary or a portable device, which can activate and pick up the signals emitted by the tags. It consists of the power unit, antenna and a PC board, and its primary role is to receive and send RF signals to the tags by 
means of an antenna. From a computer or a PLC, the reader receives instructions generated by the dedicated software. The control unit inside the reader executes the received instructions [24].

The readers differ by range and operating frequency. Similar to the tags, readers can have small range (up to several centimetres), medium range (up to 1 meter), and long range (tens of meters, with an additional antenna). In addition, there are readers equipped with potentiometer for range regulation.

The tags consist of a microchip (which stores alpha-numerical code for product/fixture labelling), an antenna (copper wire - coil) and an optional power source (e.g. battery). They exist in a variety of forms: various pendants, circular or square plates, magnetic cards, or some other form, depending on the area of application (Fig. 1). Smart labels are a special type of tags which can be placed on, or built into a palette or any sort of product/fixture.

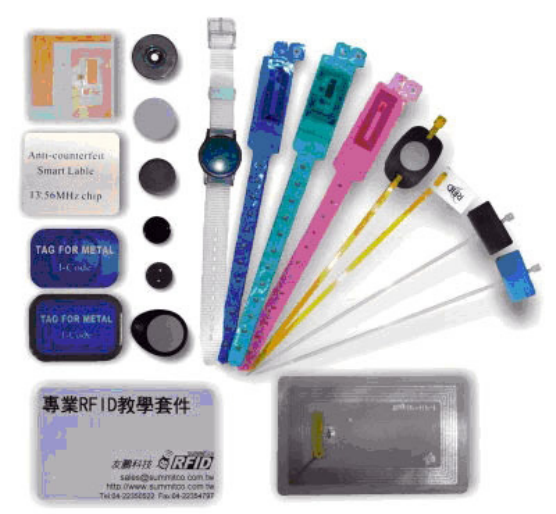

Fig. 1. Various forms of RFID tags (Summit Automation Co., Ltd.)

The components of RFID systems are selected depending on the area of application. Of primary consequence is the operating frequency of the components (Fig. 2). In most of the countries, the operating frequencies for RFID systems are strictly defined.

Bar code reading requires an operator to manipulate product/fixture in order to be detected by the reader, or to manipulate the reader itself. This requires a number of workers:

- Bar code must not have any impurities, or otherwise the reading is erroneous. This is prohibitive in an industrial environment where there are oil stains and other impurities.

- Bar code labels are often hard to place on palettes or products/fixtures.

- Finally, the greatest deficiency of a bar code is that, in case ID needs to be changed on a palette or product/fixture, a new label must be used, which increases material consumption and requires additional time to finish the operation.

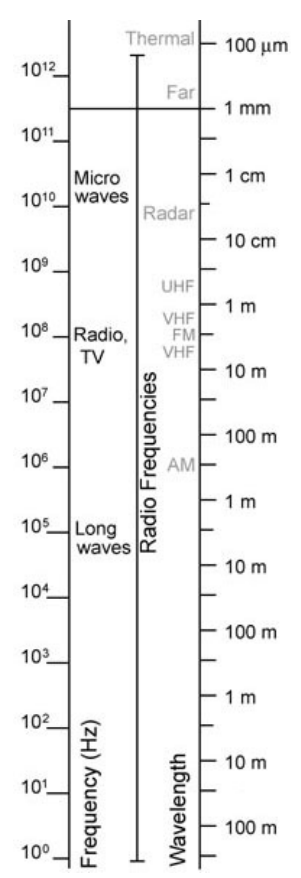

Fig. 2. Illustration showing the broad range of frequencies within the electromagnetic spectrum that RFID system can utilise

A significant advantage of RFID systems is that they do not require contact for proper functioning. Tags can be read in any industrial environment, which can involve snow, fog, ice, colour stains, dirt and similarly. RFID tags also read fast - in most cases the response is faster than 100 milliseconds. A new generation of readers have the ability to simultaneously read several tags. Thus, the whole storage area can be read at once instead of scanning each article individually. 


\section{EXPERIMENTAL RESEARCH STRUCTURE}

Considering all the advantages of RFID, especially the possibility of non-contact identification and application in an industrial (unclean) environment, this technology was chosen for fixture assembly/disassembly case study.

In production systems, where various variants of products and frequent changes of production programme are common, there is also the need for multiple changes of fixtures. Due to intensive fixture changes and the inability to store an already used fixture for further usage, it is more feasible to disassembly such a fixture and re-use its elements in a new fixture which is made for the current workpiece. With this in mind, a system was designed which should allow assembly/disassembly and inspection of fixture assembly precision in all available work stations. The system is designed bearing in mind that the assembly/disassembly and inspection operators are familiar neither with the planned tasks of fixture assembly/disassembly (fixture assembly/disassembly planning is stochastic to accommodate production requirements) nor with all the fixture variants. Instead, they use instructions especially defined for assembly/ disassembly of each particular fixture.

The system proposed in this paper for fixture assembly/disassembly and inspection consists of: four work stations which are identically equipped with tools, measurement devices, a computer which is connected to the database and an RFID reader (Fig. 3). All the work stations are interconnected by a conveyor belt which transports palette carriers, and are supplied by fixture elements from a central storage. In addition, the system also features two work stations equipped with a computer and an RFID tag. These work stations are manned by operators who take out and return fixture elements back to the storage, while also performing selection of fixture elements according to their present state.

\subsection{Fixture Assembly Procedure}

According to the scheduled plan of production, work order is sent to the storage of fixture elements which defines the required fixture with the BoM (Bill of Material). Warehouse operator takes the kitting box and selects required fixture elements from the storage. He then takes a card-shaped RFID tag and writes in the code of the work order. In this way, a direct relationship between the collected fixture elements and their assembly instructions is established. All the data are stored into a unified data base. In addition, the storage inventory state is automatically reduced by the number of issued elements, which provides efficient updating of inventory state. Subsequently, the operator inserts the RFID tag into a kitting box together with fixture elements and places the box onto palette carrier on the conveyor belt. The kitting box is then taken by the first available operator and the RFID tag is taken out. Once the RFID tag is read, the computer displays (according to work order code) assembly instructions which must be carried out. Upon the completion of assembly procedure, the operator inspects assembly precision and RFID tag is updated to indicate assembly completion. After that, the fixture is returned to the storage of finished fixtures together with its RFID tag, wherefrom the fixture is directed to the appropriate machine tool, according to the process plan. This procedure is the same for all fixtures except those whose base plate dimensions preclude them from being fitted onto conveyor belt. In such cases, the operator takes the base plate from the buffer and assemblies the rest of the fixture elements according to the work order (Fig. 3).

\subsection{Fixture Disassembly Procedure}

The used fixtures and their corresponding RFID tags arrive at the storage for fixtures that are to be disassembled. Here, they are taken by available operators and transported to their work stations. At the workstation, the operator takes the RFID tag and enters the data at the beginning of the fixture disassembly procedure. Based on the code read from the RFID tag, a sequence of disassembly instructions is drawn from the data base for the particular fixture. In the next step, the operator disassembles the fixture. Upon completion of disassembly, he takes the kitting box and places all the disassembled fixture elements into it. Then, the RFID is updated with the data on disassembly completion and the tag is inserted into the kitting 


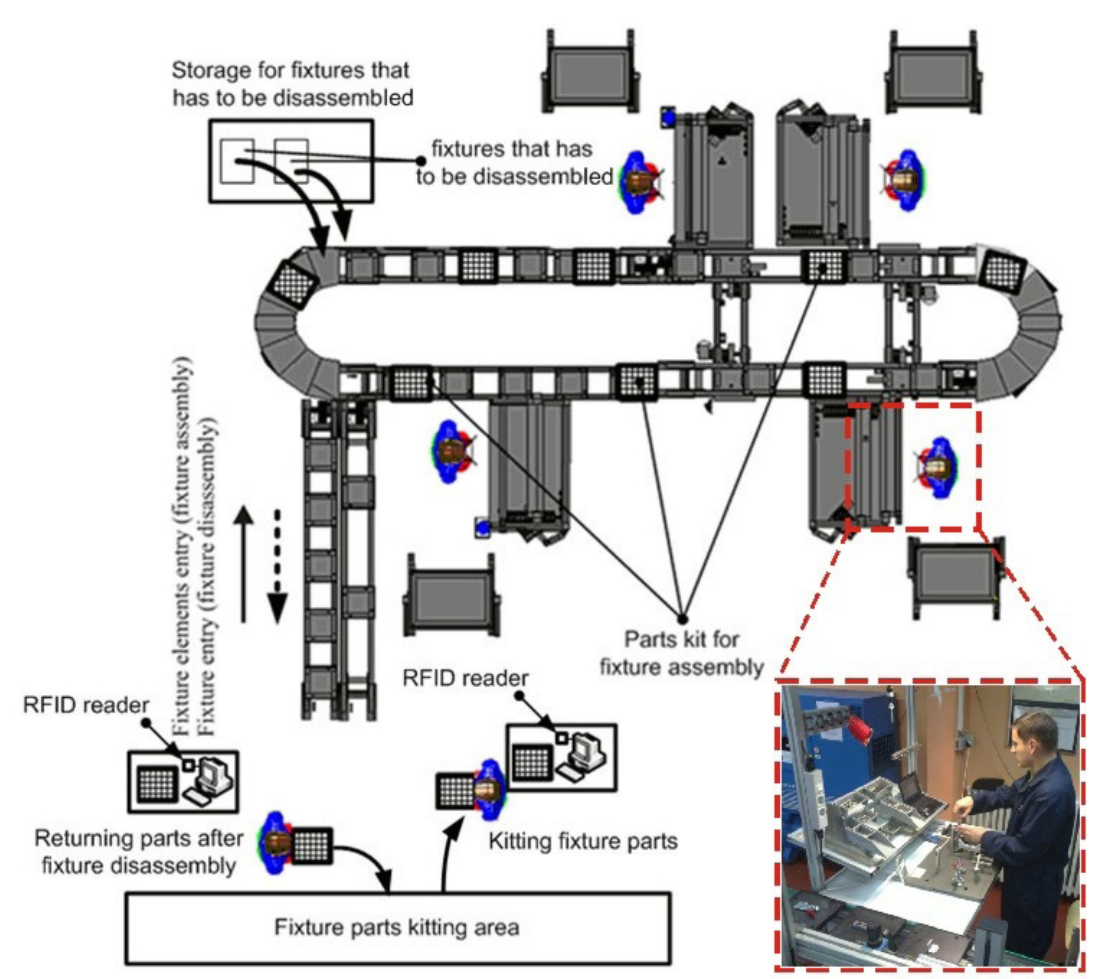

Fig. 3. Assembly/disassembly process with the use of RFID technology

box. The kitting box is placed on a palette on a conveyor belt. It is then taken by the operator in charge of the storage inventory. The operator reads the fixture BoM from the RFID tag which he took from the kitting box. He then checks the number of available elements and performs their selection. The elements which conform to the requirements (are not deformed, broken, or of the changed structure, etc.) are returned to the storage, while the rest are selected according to their state. The present state of each BoM element is established by the operator (to be returned, not to be returned to the warehouse), after which the warehouse inventory state is automatically updated. In this way, procurement of fixture elements is always up to date which directly influences production continuity (Fig. 3).

It should be emphasized that throughout its life cycle, a fixture is constantly monitored by RFID technology - from the moment of taking fixture elements from the storage and their assembly, through exploitation, up to the disassembly and return of elements to the storage.

\section{RESULTS AND DISCUSSION}

The proposed system was verified in vitro. In order to obtain relevant data, complete research was conducted under laboratory conditions. Prior to verification, a detailed study of the system was conducted. Fixtures were identified with all the necessary operations for their assembly/ disassembly. In addition, all possible strategies for the selection of fixtures and their elements were analyzed. Verification was performed on a total of 96 fixtures, which, according to applicability in certain machining operations and the similarity of assembly/disassembly sequences, could be classified into following groups:

- fixture group 1 - comprises 44 fixture design solutions for machining operations;

- fixture group 2 - comprises 52 fixture design solutions for inspection operations;

The conducted research yielded results shown in Table 1. Based on the results, the following conclusions can be drawn:

- For fixtures of Group 1, the difference in average assembly times with manual and 
RFID identification amounts to $22 \%$ in favour of RFID technology. With disassembly, the situation is similar, while the average disassembly time is $17 \%$ shorter when using RFID.

- For fixtures of Group 2, the difference in average assembly times with manual and RFID identification amounts to $21 \%$ in favour of RFID technology. With disassembly, the situation is similar, while the average disassembly time is $15 \%$ shorter when using RFID.

Table 1. System verification results

\begin{tabular}{|l|c|c|}
\hline \multirow{2}{*}{ Process } & \multicolumn{2}{|c|}{ Fixture groups } \\
\cline { 2 - 3 } & 1 & 2 \\
\hline $\begin{array}{l}\text { Average time of fixture } \\
\text { assembly (min/fixture) with } \\
\text { manual identification }\end{array}$ & 98 & 83 \\
\hline $\begin{array}{l}\text { Average time of fixture } \\
\text { assembly (min/fixture) with } \\
\text { RFID identification }\end{array}$ & 76 & 66 \\
\hline $\begin{array}{l}\text { Average time of fixture } \\
\text { disassembly (min/fixture) with } \\
\text { manual identification }\end{array}$ & 82 & 69 \\
\hline $\begin{array}{l}\text { Average time of fixture } \\
\text { disassembly (min/fixture) with } \\
\text { RFID identification }\end{array}$ & 68 & 59 \\
\hline
\end{tabular}

\section{CONCLUSIONS}

The proposed concept of the system provides complete control of materials flow related not only to the manufacturing process itself, but also to its environment. Furthermore, this concept makes the data on the number of fixtures which are to be assembled, disassembled readily available, as well as the fixture elements which can be re-used (which are already storage or are transported to the storage), fixture elements which can be reconstructed, the quantities and types of materials for recycling (quantities and types of secondary materials).

Analyzing the results of system verification in vitro, it can be noted that the ratio of percentages varies in some cases by more than $20 \%$, but is always in favour of the RFID identification, which justifies its application in the given examples. A feasibility study is required to support the idea of introducing the RFID technology into systems for fixture assembly/disassembly.

In addition, the systems, which incorporate the RFID technology, show greater flexibility in terms of the ability to accept and machine various types of fixtures, as well as other products.

Finally, the following can be concluded: the system proposed and tested in this paper performed satisfactorily with various types of fixtures, which were grouped according to similarity of sequences within the process of assembly/disassembly. It allows the reduction of the main assembly/disassembly time, which directly steps up productivity.

\section{REFERENCES}

[1] Palčič, I., Buchmeister, B., Polajnar, A. (2010). Analysis of innovation concepts in Slovenian manufacturing companies. Strojniški vestnik - Journal of Mechanical Engineering, vol. 56, no. 12, p. 803-810.

[2] Kušar, J., Berlec, T., Žefran, F., Starbek, M. (2010). Reduction of machine setup time. Strojniški vestnik - Journal of Mechanical Engineering, vol. 56, no. 12, p. 833-845.

[3] Bi, Z.M., Zhang, W.J. (2001). Flexible fixture design and automation: Review, issues and future directions. International Journal of Production Research, vol. 39, no. 13, p. 2867-2894.

[4] Župerl, U., Čuš, F. (2002). A model for analysing and optimazing fixtures. Strojniški vestnik - Journal of Mechanical Engineering, vol. 48 , no. 2, p. 73-86.

[5] Wang, Y., Xie, J.F., Wang, Z.J., Gindy, N. (2008). A parametric FEA system for fixturing of thin-walled cylindrical components. Journal of Materials Processing Technology, vol. 205, no. 1-3, p. 338-346.

[6] Kulankara, K., Satyanarayana, S., Melkote, S.N. (2002). Iterative fixture layout and clamping force optimization using the genetic algorithm. Journal of Manufacturing Science and Engineering, vol. 124, no. 1, p. 119-125.

[7] Chen, W., Ni, L., Xue, J. (2008). Deformation control through fixture layout design and clamping force optimization. The International Journal of Advanced 
Manufacturing Technology, vol. 38, no. 9-10, p. $860-867$.

[8] Padmanaban, K.P., Arulshri, K.P., Prabhakaran, G. (2009). Machining fixture layout design using ant colony algorithm based continuous optimization method. International Journal of Advanced Manufacturing Technology, vol. 45, no. 9-10, p. 922-934.

[9] Padmanaban, K.P., Prabhaharan, G. (2008). Dynamic analysis on optimal placement of fixturing elements using evolutionary techniques. International Journal of Production Research, vol. 46, no. 15, p. 4177-4214.

[10] Bugtai, N., Young, R.I.M. (1998). Information models in an integrated fixture decision support tool. Journal of Materials Processing Technology, vol. 76, no. 1-3, p. 29-35.

[11] Lin, Z.C., Yang, C.B. (1995). An expert system for fixturing design for face milling using modular fixture. The International Journal of Advanced Manufacturing Technology, vol. 10, no. 6, p. 379-388.

[12]Hu, C.Q., Lin, Z.Q., Lai, X.M. (2006). Concept design of checking fixture for auto-body parts based on neural networks. International Journal of Advanced Manufacturing Technology, vol. 30, no. 5-6, p. 574-577.

[13] Liqing, F., Kumar, A.S. (2005). XMLbased representation in a CBR system for fixture design. Computer-Aided Design \& Applications, vol. 2, no. 1-4, p. 339-348.

[14] Peng, G., Chen, G., Liu, X. (2010). Using CBR to develop a VR-based integrated system for machining fixture design. Assembly Automation, vol. 30, no. 3, p. 228239.

[15] Ameri, F., Summers, J.D. (2008). An ontology for representation of fixture design knowledge. Computer-Aided Design \& Applications, vol. 5, no. 5, p. 601-611.

[16] Vukelic, D, Župerl, U., Hodolic, J. (2009). Complex system for fixture selection, modification, and design. The International Journal of Advanced Manufacturing Technology, vol. 45, no. 7-8, p. 731-748.

[17] Liou, F.W., Suen, D. (1992). The development of a feature-based fixture process planning system for flexible assembly. Journal of Manufacturing Systems, vol. 11, no. 2, p. 102113.

[18] Ma, W., Lei, Z., Rong, Y. (1998). FIX-DES: A computer-aided modular fixture configuration design system. The International Journal of Advanced Manufacturing Technology, vol. 14, no. 1, p. 21-32.

[19] Kakish, J., Zhang, P.L., Zeid, I. (2000). Towards the design and development of a knowledge-based universal modular jigs and fixtures system. Journal of Intelligent Manufacturing, vol. 11, no. 4, p. 381-401.

[20]Dai, J.R., Nee, A.Y.C., Fuh, J.Y.H., Kumar, A.S. (1997). An approach to automating modular fixture design and assembly. Proceedings of the Institution of Mechanical Engineers, Part B: Journal of Engineering Manufacture, vol. 211, no. 7, p. 509-521.

[21] Wu, Y., Rong, Y., Ma, W., LeClair, S.R. (1998). Automated modular fixture planning: Geometric analysis. Robotics \& ComputerIntegrated Manufacturing, vol. 14, no. 1, p. 1-15.

[22]Peng, G., He, X., Yu, H., Hou, X., Khalil, A. (2008). Precise manipulation approach to facilitate interactive modular fixture assembly design in a virtual environment. Assembly Automation, vol. 28, no. 3, p. 216-224.

[23] Herakovič, N. (2007). Computer and machine vision in robot-based assembly. Strojniški vestnik - Journal of Mechanical Engineering, vol. 53 , no. 12 , p. 858-873.

[24] Ostojic, G., Lazarevic, M., Stankovski, S., Cosic, I., Radosavljevic, Z. (2008). Radio frequency identification technology application in disassembly systems. Strojniški vestnik - Journal of Mechanical Engineering, vol. 54, no. 11, p. 759-767. 